\title{
Formação Serra Geral (Cretáceo da Bacia do Paraná): um análogo para os reserva- tórios ígneo-básicos da margem continental brasileira
}

\author{
Gleice S. REIS, Ana M. MIZUSAKI, Ari ROISENBERG \& Rogério R. RUBERT
}

Programa de Pós-Graduaçao em Geociências, Instituto de Geociências, Universidade Federal do Rio Grande do Sul. Caixa Postal 15001, CEP 91509-900, Porto Alegre, RS, Brasil. E-mail: gleicegel@gmail.com, ana.mizusaki@ufrgs.br, ari.roisenberg@ufrgs.br, rogrubert@yahoo. com.br.

Recebido em 03/2013. Aceito para publicação em 08/2014.

Versão online publicada em 19/09/2014 (www.pesquisasemgeociencias.ufrgs.br)

\begin{abstract}
Resumo - 0 estudo das rochas ígneas é de especial interesse nas bacias sedimentares produtoras de hidrocarbonetos pela possibilidade de constituírem reservatórios vulcânicos não convencionais. Na Bacia de Campos, situada na margem continental sudeste do Brasil, os campos de Badejo e Linguado produzem a partir de reservatórios vulcânicos fraturados que se constituem no seu embasamento econômico. São derrames de rochas básicas, vesiculares, fraturados e intercalados por intertraps arenosos. Estes campos produtores são offshore e o reservatório não convencional encontra-se a grandes profundidades, submerso, dificultando o entendimento tanto do modelo bem como do sistema permo-poroso responsável pela acumulação do hidrocarboneto. Assim, há necessidade de um modelo análogo em superfície que permita a visualização e o entendimento do reservatório e das feições permo-porosas. A Formação Serra Geral (vulcanismo do Cretáceo da Bacia do Paraná) é considerada como o modelo análogo para reservatórios vulcânicos fraturados. Com base no estudo de afloramentos de rochas vulcânicas dessa formação nas regiões do Salto do Jacuí e Torres, no estado do Rio Grande do Sul e no emprego de técnicas petrográficas, geoquímicas, de difratometria de raios X e de microscopia eletrônica de varredura é proposto um modelo análogo. No presente modelo, falhas, fraturas, vesículas e microfraturas constituem o sistema permo-poroso e permitem o entendimento de diversos reservatórios não convencionais em sub-superfície, especialmente os vulcânicos.
\end{abstract}

Palavras-chave: rocha reservatório, Bacia do Paraná, análogo, hidrocarbonetos, bacias marginais costeiras.

\begin{abstract}
Serra Geral Formation (Cretaceous, Paraná Basin) - an analogous for igneous-basic RESERVoIRs of THE BRAZILIAN Continental MARGin. The study of igneous rocks is of special interest in sedimentary basins with hydrocarbon production due to the possibility of being unconventional volcanic reservoirs. The fields of Badejo and Linguado of the Campos Basin, located in the southeastern continental margin, produce hydrocarbons from fractured volcanic reservoirs that represent their economic basement. They comprise flows of fractured basic rocks, vesicles and intercalations of arenaceousintertraps. These production fields are offshore and the unconventional reservoir is submerged at great depths, making difficult to understand both the model and the permo-porous system. Thus, it is necessary to provide an analogous model in subsurface in order to allow the visualization and the understanding of the reservoir and the permoporous features. The Serra Geral Formation (volcanism recorded in the Cretaceous of the Paraná Basin) is considered an analogous model to fractured volcanic reservoir. Taking this into account, we propose herein an analogous modelbased on the study of volcanicsoutcroups of this formation, located in the Salto do Jacui and Torres regions, Rio Grande do Sul State, allied to the use of petrographic and geochemistry techniques, $\mathrm{X}$-ray diffractometry and scanning electron microscopy. In the present model, faults, fractures, vesicles and microfractures constitute the permo--porous system that allows the understanding of various unconventional reservoirs in sub-surface, specially the volcanic reservoirs.
\end{abstract}

Keywords: reservoir rocks, Paraná Basin, analogous, hydrocarbons, marginal coastal basins.

\section{Introdução}

\subsection{Considerações gerais}

Manifestações magmáticas são comuns nos diferentes períodos geológicos da evolução das bacias sedimentares, especialmente aquelas nas margens de placas divergentes e nas do tipo rifte. Nos últimos anos, tem sido de considerável importância o reconhecimen- to e o estudo destes eventos nas bacias produtoras de hidrocarbonetos, nas quais as rochas vulcânicas podem causar tanto impactos negativos como positivos. Como impactos negativos, consideram-se as alterações nas propriedades permoporosas dos reservatórios adjacentes, associadas com o aumento de temperatura, verificadas quando das extrusões e intrusões magmáticas. Do ponto de vista positivo, eventos magmáticos podem incrementar gradualmentea a temperatura da área e assim acelerar a maturação dos hidrocarbonetos 
nas rochas geradoras próximas (Jinglan et al., 1999).

No entanto, em bacias produtoras de hidrocarbonetos, as rochas vulcânicas ainda podem atuar como cap rocks e como rochas-reservatório. Muitos dos reservatórios atualmente conhecidos em rochas ígneas resultaram de descobertas acidentais, uma vez que a chance de encontrar hidrocarbonetos em rochas deste tipo sempre foi considerada remota. No entanto, atualmente, vem se observando um crescente e importante número de descobertas onde as rochas vulcânicas são reservatórios de hidrocarbonetos (Schiuma, 1988). As rochas ígneas quando reservatórios de hidrocarbonetos são genericamente denominadas de "embasamento" e os reservatórios considerados como secundários (P’An, 1983).

Assim, há necessidade de entendimento destas rochas sob o ponto de vista de reservatório não-convencional e o desenvovimento de modelos que permitam um melhor conhecimento do sistema permoporoso e, consequentemente, a melhor explotação destas reservas.

Na Bacia de Campos, margem continental sudeste do Brasil, os campos produtores de Badejo e Linguado tem o embasamento econômico atual constituído por derrames de rochas básicas que apresentam produção de hidrocarbonetos, ou seja, constituem um reservatório não convencional (Mizusaki, 1986) (Fig. 1).

0 reservatório é secundário e formado por uma sucessão de derrames de basalto alterados e fraturados que constituem o considerado embasamento econômico atual da bacia (Mizusaki, 1986). Esses campos produtores são offshore e o reservatório não convencional encontra-se a grandes profundidades, submerso, dificultando o entendimento e os processos que levaram à acumulação do hidrocarboneto nos derrames. Assim há necessidade de um modelo análogo em superfície que permita a visualização e o entendimento das feições permo-porosas do reservatório não convencional.Por isso, o principal foco deste trabalho é a análise tectono-estratigráfica integrada da Formação Serra Geral (vulcanismo do Cretáceo da Bacia do Paraná, Fig. 1) sob o ponto de vista de rocha-reservatório visando à proposição de modelos análogos para o vulcanismo Neocomiano das bacias marginais brasileiras.

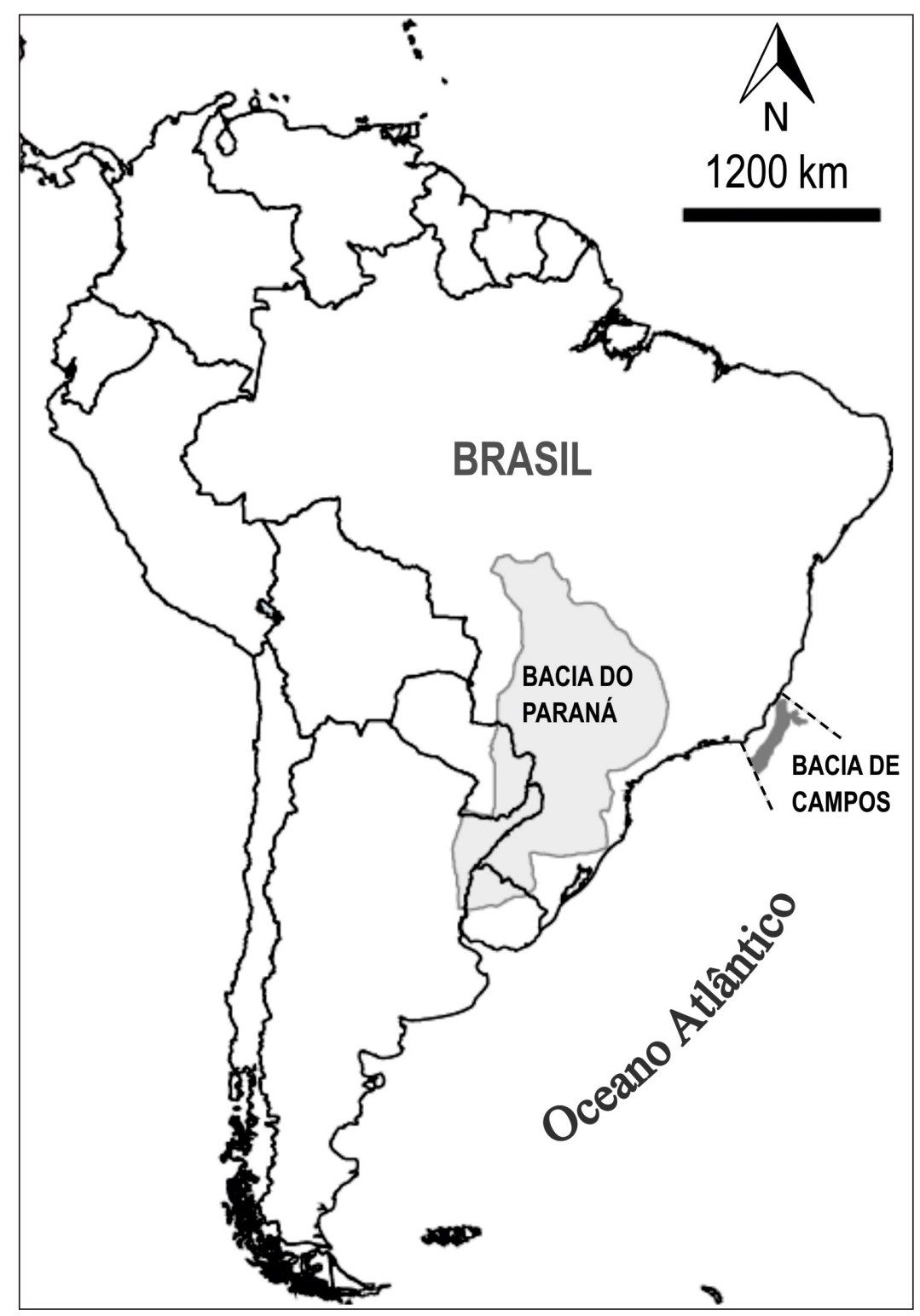

Figura 1. Localização das bacias do Paraná e de Campos (mod. Milani, 1997). 


\subsection{Rochas vulcânicas como reservatório não convencional}

Reservatório é a rocha que possuindo uma combinação apropriada de valores de porosidade e permeabilidade, possibilita a acumulação de hidrocarbonetos (óleo ou gás). Porosidade é o volume de espaços vazios, em termos de porcentagem, medido em relação ao volume total da amostra da rocha. A porosidade da rocha é definida como a capacidade em armazenar fluidos no seu interior e pode ser primária ou secundária. A porosidade primária é uma característica inerente à própria rocha, enquanto a porosidade secundária resulta de processos tais como dissolução, recristalização ou fraturamento, que ocasionam o aumento do espaço poroso primário.

Permeabilidade é a medida da capacidade da rocha em permitir o fluxo de fluidos, expressa em unidades Darcy. Como a porosidade, a permeabilidade também pode ser primária ou secundária. A permeabilidade primária está relacionada ao espaço poroso inicial da rocha. A permeabilidade secundária corresponde ao aumento dos valores iniciais de permeabilidade por fraturamento ou dissolução.

As rochas sedimentares são consideradas como reservatórios convencionais de hidrocarbonetos. No entanto, as rochas ígneas extrusivas podem se constituir em um tipo especial de reservatório de hidrocarbonetos denominado não convencional (P’An, 1983).

Supunha-se que as intrusões e extrusões de material magmático nas bacias sedimentares, na realidade, ocasionavam a destruição da matéria orgânica, dos hidrocarbonetos previamente gerados e ainda, que os fluidos associados poderiam obliterar os eventuais poros das rochas-reservatório adjacentes. No entanto, rochas magmáticas vêm ganhando destaque na geologia do petróleo, isto porque um crescente número de descobertas mundiais de hidrocarbonetos tem sido observado onde estas rochas se constituem em reservatórios de hidrocarbonetos (Mizusaki, 1986; Gu et al., 2002).

Normalmente, as rochas ígneo-básicas constituem um reservatório em que predomina um intenso sistema de fraturas interligadas, gerando espaços vazios (porosidade) e também boa permeabilidade ao reservatório. Secundariamente, outras fontes de porosidade podem ser identificadas, como as vesiculares e a porosidade da matriz alterada, desde que esses espaços vazios sejam interconectados e permitam o desenvolvimento de permeabilidade (Mizusaki, 1986). Assim, intervalos de rochas vulcânicas com vesículas, microfraturas e fraturas bem desenvolvidas e conectadas podem servir de possíveis zonas de reservatório (Sircar, 2004). Além disso, processos de intemperismo muito atuantes nestes intervalos contribuem no sentido do aumento da microporosidade.

Os campos de Badejo e Linguado da Bacia de Campos, margem continental brasileira, são bons exemplos de produção de hidrocarbonetos em reservatórios com este sistema permoporoso (Fig. 2). São derrames fratu- rados associados ao vulcanismo jurocretáceo que deu origem à Formação Cabiúnas (Mizusaki et al., 1992). 0 preenchimento deste reservatório ocorreu a partir de um intenso falhamento que colocou em contato lateral os geradores e os derrames básicos. Este tipo de reservatório foi um dos objetivos principais no inicio da exploração da bacia, mas depois ficou em segundo plano em virtude do sucesso obtido com outros prospectos (Eiras \& Wanderley Filho, 2006).

De uma forma geral, as rochas ígneo-básicas constituem um reservatório fraturado (onde predomina a porosidade por fraturamento), pois a porosidade e a permeabilidade são essencialmente dominadas por fraturas. No entanto, secundariamente, outras fontes de porosidade são identificadas: vesicular e da matriz.

\subsection{A Bacia do Paraná e a Formação Serra Geral}

A Bacia do Paraná, abrangendo aproximadamente $1.400 .000 \mathrm{~km}^{2}$, estendendo-se pelo Brasil, Paraguai, Uruguai e Argentina, constitui-se de uma vasta área de sedimentação paleozoica-mesozoica. 0 registro estratigráfico desta bacia consiste basicamente de cinco sequências deposicionais principais que variam, em idade, do Ordoviciano ao Cretáceo. É importante frisar que seu preenchimento sedimentar é predominantemente siliciclástico, sendo capeado pelas rochas vulcânicas da Formação Serra Geral. Os derrames de lavas basálticas desta unidade representam uma das maiores manifestações vulcânicas episódicas de caráter básico do Neocomiano; registram uma espessura total de até 2.000 $\mathrm{m}$ de basalto sobre os sedimentos da Bacia do Paraná, sendo principalmente representadas por derrames de natureza básica e subordinadamente por rochas ácidas. Também ocorreu significativa atividade ígnea intrusiva (representada por sills e diques) associada. Encontram-se em contato concordante e abrupto com os arenitos eólicos subjacentes da Formação Botucatu. É comum, nas porções mais basais da sequência vulcânica, a presença de intertraps deste arenito em meio aos derrames de lava, cuja origem parece estar relacionada a um intervalo de quiescência do vulcanismo. Feições de interação lava-sedimento como brechas e os denominados diques de arenito também são observados.

A Formação Serra Geral (Bacia do Paraná, Cretáceo, com aproximadamente 133 Ma segundo Renne et al., 1992), é contemporânea a este vulcanismo neocomiano das bacias marginais brasileiras e suas feições texturais e estruturais estão expostas em excelentes afloramentos, o que não ocorre com o magmatismo das bacias marginais (Mizusaki, 1986). Com isto, as microestruturas vulcânicas como poros (vesículas), fraturas e descontinuidades, típicas de eventos vulcânicos, consideradas como responsáveis pela permoporosidade deste tipo de rocha, podem ser analisadas em detalhe. As rochas vulcânicas da Bacia do Paraná estão expostas tanto verticalmente quanto lateralmente em áreas de extensão considerável e, por isto, apresentam potencial 
para uma amostragem sequencial objetivando diversos tipos de estudos e análises (química, microscopia ótica, difração de raios X, microscopia eletrônica de varredura, entre outras).

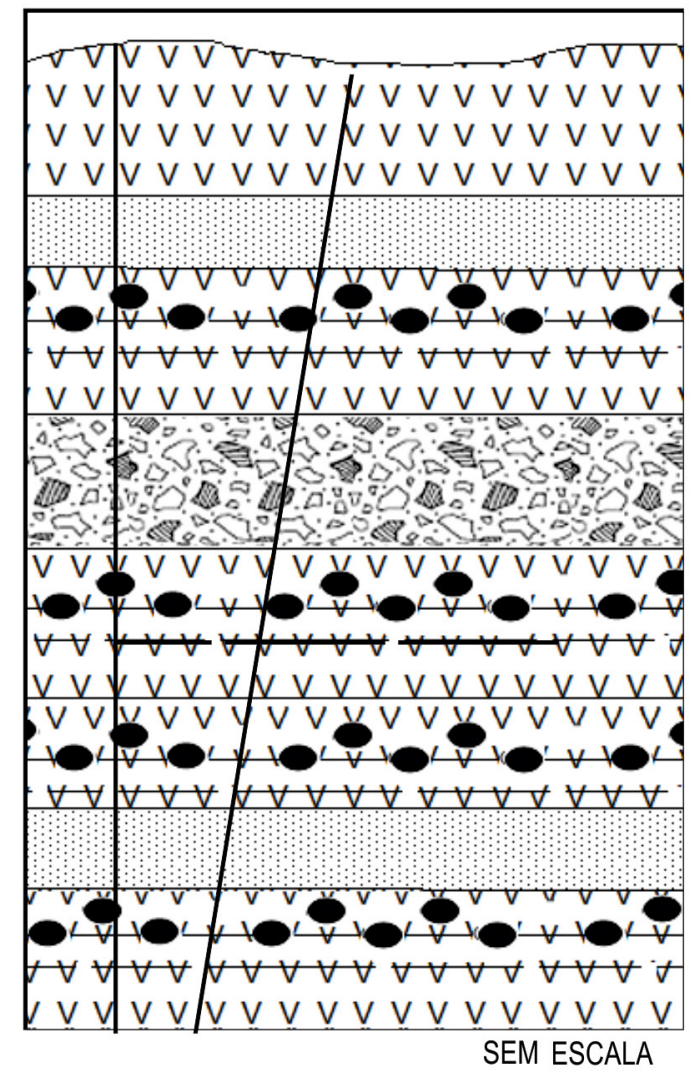

LEGENDA

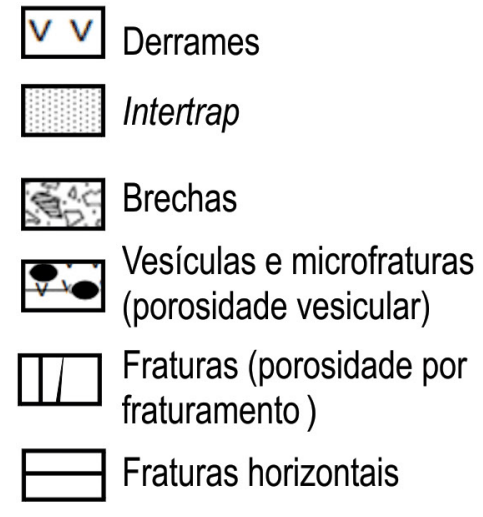

Figura 2. Modelo para o reservatório vulcano-sedimentar do Neocomiano da Bacia de Campos (mod. Mizusaki, 1986).

Nas bacias sedimentares da margem continental brasileira, o processo de rifteamento, que do Neojurássico ao Eocretáceo deu origem ao Oceano Atlântico Sul, foi marcado por inúmeros eventos magmáticos, especialmente registrados nos altos estruturais que as separam e também no continente emerso adjacente. Esses eventos são bem conhecidos nas áreas continentais emersas. No entanto, na área marginal submersa, o conhecimento depende da disponibilidade e da análise de testemunhos de sondagens obtidos, em sua maioria, pela Petrobras quando da prospecção de hidrocarbonetos (Mizusaki et al., 2002).
A Bacia do Paraná permite a elaboração de um modelo de reservatório vulcânico que pode ser aplicado nas bacias da margem continental brasileira e, mesmo, nas outras bacias paleozoicas brasileiras.

\section{2 Área, materiais e métodos}

Para a realização deste trabalho foram escolhidas duas áreas da Bacia do Paraná devido às suas características tectonoestratigráficas, destacando-se o intenso fraturamento e a presença de vesículas, feições de interesse para um análogo de rochas-reservatório (Fig. 3A). Além disso, observa-se a presença abundante de feições de interação entre os basaltos da Formação Serra Geral e os arenitos da Formação Botucatu. A área de estudo 1 localiza-se na região do Salto do Jacuí, porção central do estado do Rio Grande do Sul. O levantamento estratigráfico, tectônico e coleta de amostras abrange desde as proximidades da cidade de Santa Cruz do Sul até o Salto do Jacuí (Fig. 3B), com distâncias que variam de 155 a 284 km, respectivamente, em relação a Porto Alegre, capital do estado. Esta região foi selecionada pela presença de intertraps, fraturas, vesículas e interações dos derrames com o arenito Botucatu formando estruturas consideradas interessantes para um modelo de reservatório não convencional. A área de estudo 2 (Fig. 3C) compreende a região entre as cidades de Torres (RS), Criciuma (SC) e Cambará do Sul (RS) incluindo-se aí a Serra do Rio do Rasto (SC). Esta região foi selecionada devido ao intenso fraturamento observado bem como a presença de estruturas resultantes da interação das lavas com o arenito Botucatu.

Os trabalhos de campo foram conduzidos no sentido de obter-se dados geológicos, através da descrição detalhada das unidades aflorantes, confecção de perfis colunares, documentação fotográfica, medidas de atitudes e orientações de fraturas e falhas.A coleta de amostras de rochas para análises petrográficas, químicas, por difratometria de raios X e microscopia eletrônica de varredura também foi efetuada nesta etapa. Os dados de campo obtidos foram aplicados para a elaboração de mapas de pontos, de localização e de estruturas. Isto foi integrado através das observações de campo, das descrições dos afloramentos e das informações dos mapas geológicos anteriores, bem como uma interpretação de imagem CIBERS integradas com dados fisiográficos e geológicos obtidos de órgãos institucionais (SIG-CPRM e SIG-IBEGE). Estes dados foram tabulados para um sistema X, de coordenadas UTM, utilizando-se para este fim o Software Microsoft Excel, sendo posteriormente plotado sobre bases geológicas e imagens de satélite. As análises das imagens do modelo digital do terreno (DEM -digital elevationmodel) possibilitaram a interpretação de aspectos fisiográficos tais como drenagens e na interpretação de morfoestruturas auxiliando assim na interpretação estrutural da área.Essas imagens foram georreferenciadas no Sistema UTM (South American 1969, Datum 22 e 23, do Hemisfério 
Sul) utilizado-se para este fim os softwares MAPINFO professional 11.0, Global Mapper 7.0 e Discovery 12.0. As amostras coletadas nas etapas de campo foram descritas macroscopicamente em lupa Wild Heerbrugg e fotodocumentadas. Foi feita então uma seleção de amostras para serem analisadas por técnicas petrográficas, por difratometria de raios X e por microscopia eletrônica de varredura visando à obtenção de dados complementares.

Os grupos de argilominerais presentes nas amostras selecionadas foram identificados com base na sua estrutura cristalina utilizando-se um difratômetro Siemens D5000 Diffraktometer pertencente ao Laboratório de Difratometria de Raios X do Instituto de Geociências da Universidade Federal do Rio Grande do Sul, com radiação $\mathrm{K} \alpha \mathrm{Cu}$ nas condições de $40 \mathrm{kV}$ e $30 \mathrm{~mA}$ de corrente de filamento e no intervalo de 2 a $28^{\circ}(2 \theta)$. Fragmentos milimétricos das amostras foram colados (com epóxi) em porta amostras especiais e metalizados com fina película de ouro para análise ao microscópio eletrônico de varredura. São observados em aumentos variáveis (em geral até $10.000 \mathrm{X}$ ) e fotografados.
As análises foram realizadas no Centro de Microscopia Eletrônica da Pontifícia Universidade Católica do Rio Grande do Sul (PUC-RS).

Em campo foram efetuados perfis regionais com descrição de estruturas segundo suas características morfológicas, relações no pacote de rocha, dimensões e disposição espacial (atitudes). Para a análise estatística dos dados estruturais de campo para esta área utilizou-se bússola Brunton com notação de mão esquerda. Posteriormente, os dados foram compilados e processados através do Software Stereonet, a partir do qual foram gerados os estereogramas com padrão de dispersão tipo roseta, com os dados de cada bloco nele plotados. Para fins de análise, foram consideradas estruturas rúpteis ocorrentes nas quais englobam-se plano de falhas, fraturas e juntas. Na área de estudo 1 foram obtidas 51 medidas em afloramentos e na área de estudo 2, foram 131 medidas. Por outro lado, a interpretação de morfoestruturas foi realizada utilizando-se imagens de Modelo Digital do Terreno em escala de cores e escala de cinza, com os softwares Mapinfo 10.5 e EnconDiscover 12.0, levando-se em conta padrões de
A

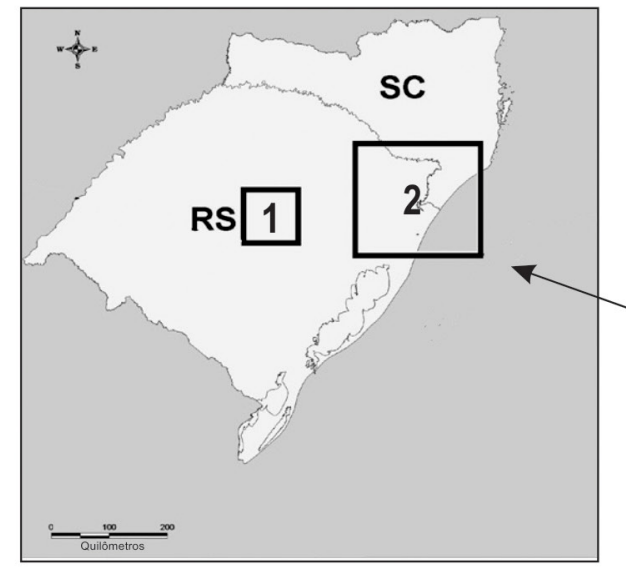

Área de estudo 1

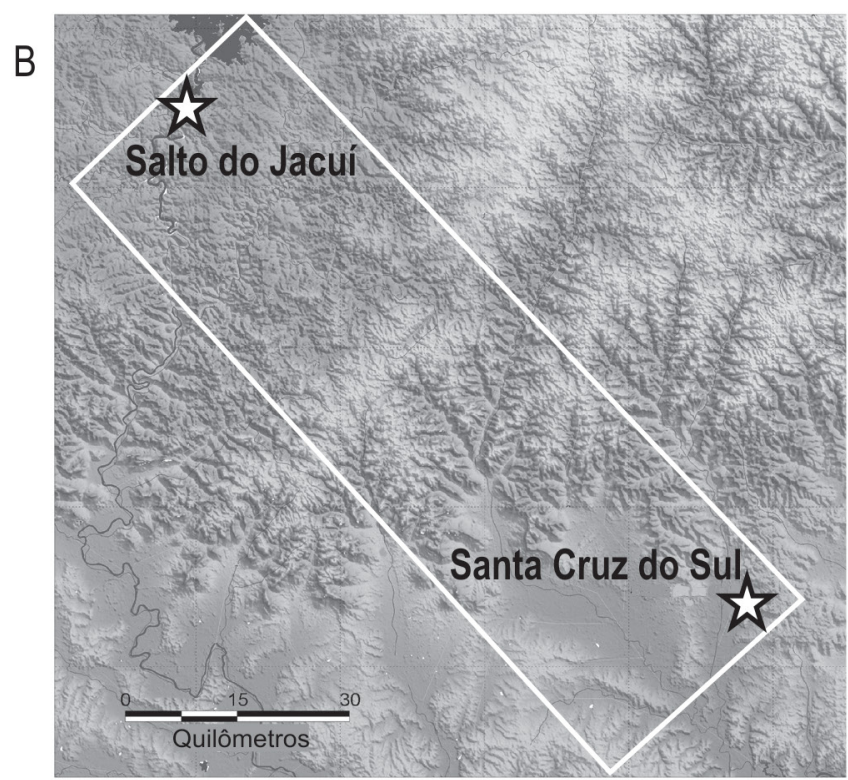

Área de estudo 2

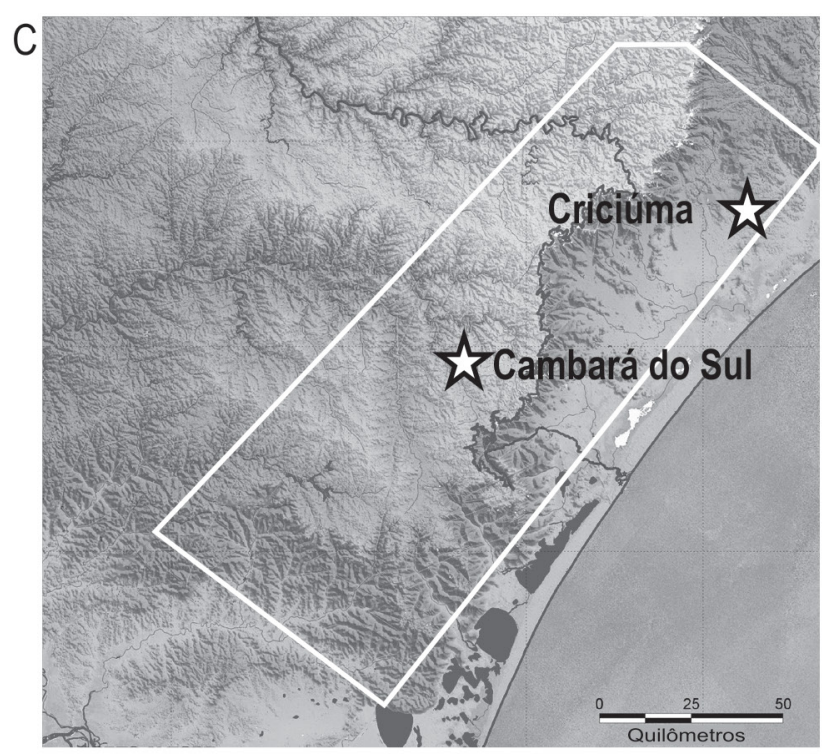


drenagem, níveis de erosão diferencial e elementos gerais do relevo. A partir da interpretação realizada foram individualizadas morfoestruturas (lineamentos), levando-se em conta sua densidade na área, amplitude regional, continuidade e direções predominantes. Conceitualmente entende-se como morfoestruturas o produto da influência da estrutura litológica na gênese das formas de relevo, principalmente aquelas relacionadas à ação da dinâmica das províncias geológicas (Ross, 1985, 1992). Dentre as variadas formas desenvolvidas em um terreno através da interação intemperismo, erosão e controle litológico e estrutural destacam-se os lineamentos.

\section{Resultados}

\subsection{Modelos análogos}

O desenvolvimento de modelos análogos compreende o estudo de sucessões expostas que, em subsu- perfície, apresentam potencialidade para a exploração de hidrocarbonetos. Isto permite que sejam produzidos modelos para o entendimento dos reservatórios que estão em subsuperfície e não são integralmente visualizados. Este é o caso dos reservatórios ígneo-básicos do Neocomiano da Bacia de Campos que se encontram em profundidades superiores a $3.600 \mathrm{~m}$ na margem continental, cujo modelo é proposto a partir da análise de alguns testemunhos e perfilagem.

Na Bacia de Campos, a Formação Cabiúnas, reservatório vulcano-sedimentar do Neocomiano, indica o empilhamento de derrames de composição básica (espessuras médias em torno de $4 \mathrm{~m}$ definidas através da análise de perfilagem), com intercalações de arenitos vulcânicos e vulcanoclásticas (Fig. 4A). São interpretados como sequências de derrames basálticos intercalados com rochas vulcanoclásticas e sedimentares onde a porosidade principal está associada ao intenso fraturamento (Mizusaki, 1986).
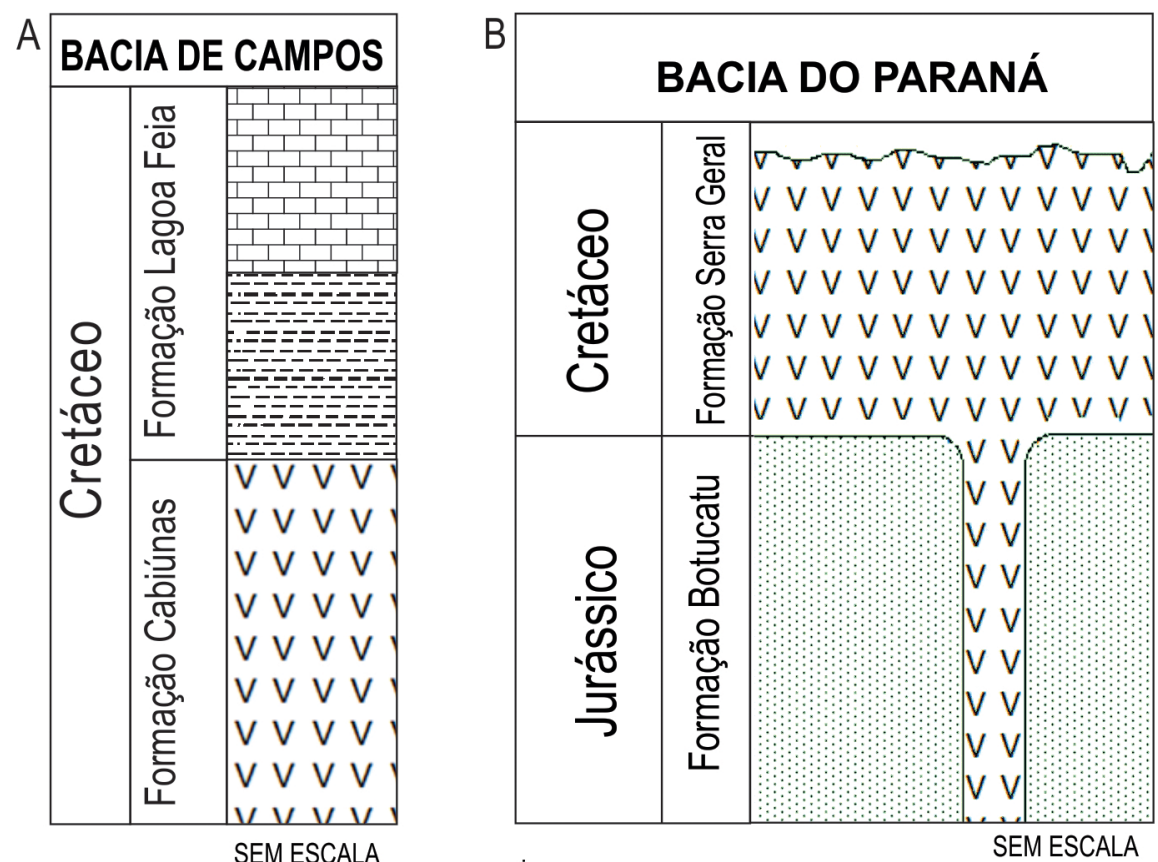

\section{LEGENDA}

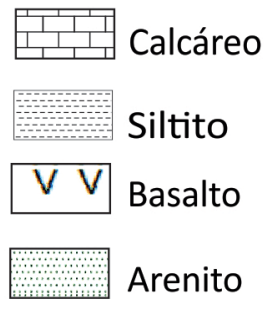

Figura 4. Comparação dos intervalos estudados nas colunas estratigráficas: A) Bacia de Campos; B) Bacia do Paraná.

O sistema permoporoso seria constituído por um intenso processo de fraturamento associado à porosidade das zonas vesiculares (porosidade vesicular). $\mathrm{Na}$ zona vesicular, microfraturas resultantes do processo de resfriamento conectam as vesículas e conferem permeabilidade a esta porção.

Como as rochas ígneo-básicas da Bacia do Paraná tem características semelhantes (Fig. 4B), estão expostas tanto verticalmente quanto lateralmente em áreas de extensão considerável e apresentam potencial para uma amostragem sequencial objetivando diversos tipos de estudos e análises (química, microscopia ótica, difração de raios X, microscopia eletrônica de varredura, entre outras), podem ser análogos para estudo destas feições de permoporosidade (Mizusaki et al., 2002).

\subsection{A Formação Serra Geral nas áreas de estudo}

A sequência vulcânica da Bacia do Paraná, na região de estudo, é encontrada sob a forma de derrames tabulares, algumas vezes lenticulares, de lavas de composição básica, textural e composicionalmente representadas por rochas basálticas. Na região do Salto do Jacuí, ocorre no topo da sequência vulcânica a presença de derrames de composição dacítica identificando o Membro Palmas (Bellieni et al., 1986). Nos derrames basálticos individuais pode-se observar diferenças texturais que são marcantes especialmente nos derrames mais espessos ( $>6 \mathrm{~m}$ ). As porções de base e topo apresentam uma textura mais vítrea enquanto as porções centrais têm uma textura holocristalina, com 
o tamanho dos cristais variando de milimétricos até 1 cm. Nos derrames de composição mais ácida (dacitos), esta diferenciação é pouco observada pois predomina uma textura hemicristalina com abundante matriz vítrea. São observadas vesículas, cavidades milimétricas a centimétricas, formas arredondadas ou ovaladas, concentradas especialmente na porção mais superior dos derrames. Na porção basal e central dos derrames, principalmente aqueles de menor espessura, também podem ser observadas, porém em menor volume em relação ao topo dos derrames. As vesículas podem estar abertas, parcial ou totalmente preenchidas por material de origem secundária (argilominerais, quartzo, calcita, zeolitas, ametista, entre outros). Podem também estar orientadas, indicando o fluxo, e há uma tendência de aumento do diâmetro em direção às porções mais superiores dos derrames. Associando-se às vesículas, preferencialmente as do topo dos derrames, são observadas microfraturas. As microfraturas parecem ser originadas pela contração térmica durante o resfriamento das lavas e formam uma rede unindo as vesículas. Nos derrames dacíticos, as vesículas são pouco representativas, muitas vezes estão orientadas; as microfraturas não são tão comuns quanto nos derrames basálticos.

Nos derrames individuais, em alguns casos, observa-se o diaclasamento, ou seja fraturas originadas du- rante o processo de resfriamento (Fig. 5A). 0 derrame, na medida em que perde calor, pode ter uma contração de até $10 \%$ de seu volume, produzindo rupturas e dando origem a fraturas, denominadas disjunções. As colunas formadas são ortogonais ao topo e à base do derrame e tendem a um formato hexagonal. Em derrames espessos, entre as duas zonas colunares permanece uma zona não atingida pela disjunção, chamada de entablamento, região central ou miolo, conforme já observado por Fernandes et al. (2010).

Intercalados aos derrames, principalmente na base da seção vulcânica, ocorrem intertraps de arenito que representam intervalos de quiescência durante a atividade vulcânica e consequente recorrência dos processos sedimentares (Picheler, 1952; Suguio \& Fúlfaro, 1974; Waichel et al., 2006; Petry et al., 2007). São camadas de arenito de cor rosa, quartzoso e localmente, com uma incipiente estratificação cruzada atribuídos à Formação Botucatu (Fig. 5B). Os derrames de lava, especialmente na porção mais basal da Formação Serra Geral, cobriram e preservaram a morfologia das dunas eólicas do antigo deserto Botucatu ocasionando a presença de intertraps arenosos. Eventualmente as dunas ficam preservadas e podem ser vistas em macroescala, evidenciadas por variações da espessura e estruturas associadas conforme descrito por Scherer (1998).
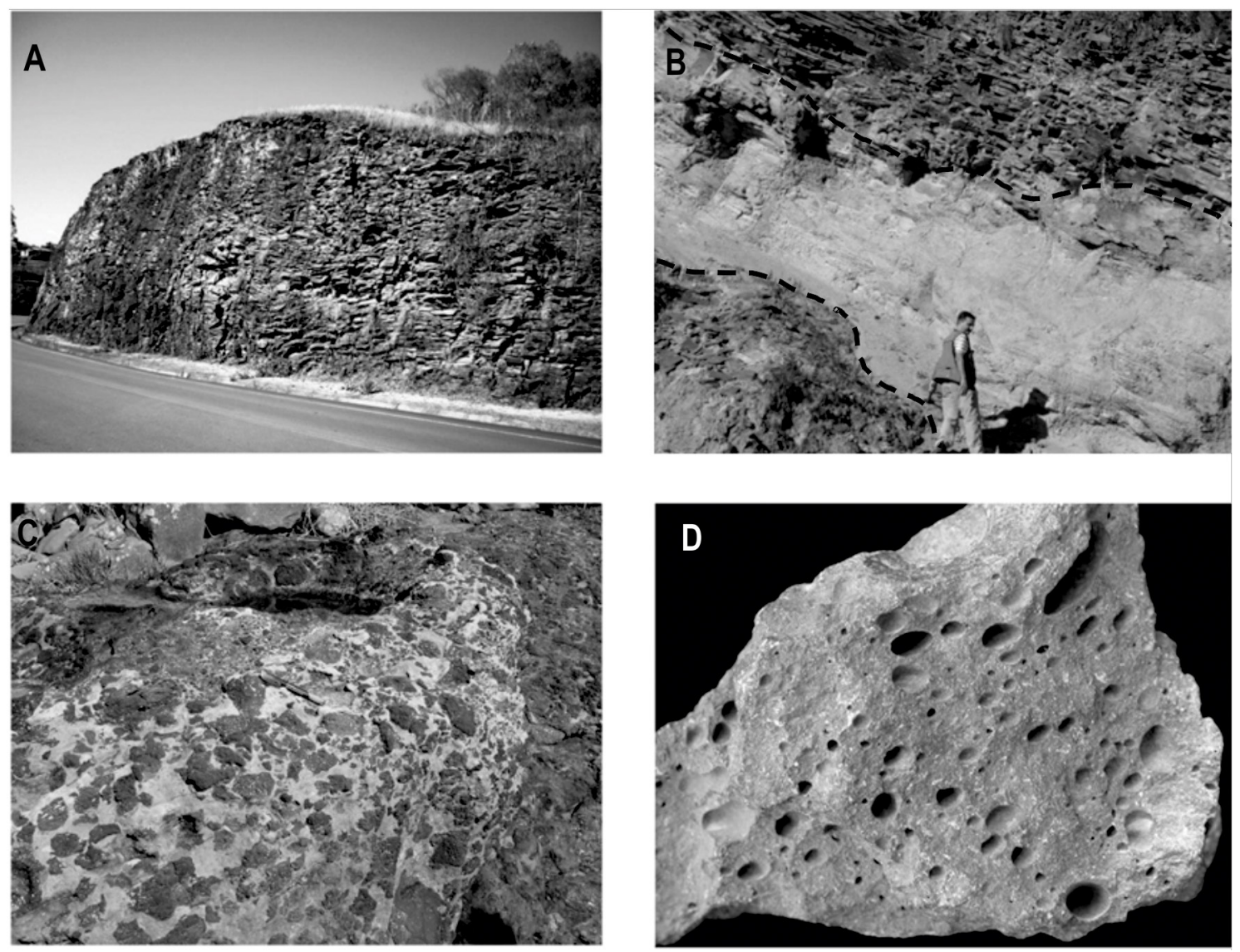

Figura 5. Detalhes do sistema permoporoso: A) derrame mostrando diaclasamento (associado com o processo de resfriamento); B) intertrap arenoso; C) brecha resultante da interação lava e sedimentos; D) clasto de basalto com vesículas e porosidade vesicular. 
Da interação das lavas com os sedimentos intertrap, destacam-se os diques de arenito, fraturas e geodos com sedimentos e as brechas (Fig. 5C). Como diques de arenito foram designadas as fraturas verticalizadas cuja espessura varia de milimétrica a centimétrica, preenchidas por sedimentos (Michelin, 2013). Desenvolvem-se da base para o topo dos derrames individuais mas sempre a partir da presença de intertraps arenosos bem desenvolvidos, eventualmente com a presença de brechas associadas.Os sedimentos que preenchem as fraturas têm cor rosa a castanha, são essencialmente quartzosos, de granulometria fina a média. Os diques de arenito podem ser cimentados por sílica, quando então ficam mais resistentes ao intemperismo podendo ressaltar-se na superfície.Uma das hipóteses da gênese desses diques é encontrada no trabalho de Picheler (1952), pelo qual estes se formam concomitantemente ao derrame. 0 magma relativamente fluido cobre uma camada de areia inconsolidada saturada com água (intertrap arenoso) e, as altas temperaturas associadas com o processo, são responsáveis pela vaporização da água. A água vaporizada tem uma elevada pressão e fica trapeada na base do derrame. No entanto, qualquer fraturamento da rocha vulcânica, que acontece durante o processo de resfriamento, ocasiona a expulsão desta água vaporizada que carreando os sedimentos, irá preencher as fraturas de baixo para cima com areia. As relações de contato entre os arenitos e basaltos da Formação Serra Geral permitiram a Suguio \& Fúlfaro (1974) também propor um modelo semelhante para a formação destes diques.

Já a denominação de "fraturas preenchidas com sedimentos arenosos" mostra, ao contrário dos diques de arenito uma ocorrência sempre do topo para a base dos derrames. Não são muito extensas e caracterizam-se por paredes mais retilíneas, bem marcadas e sem alterações significativas. 0 sedimento de preenchimento é um arenito quartzoso, granulometria fina a média, de cor rosada e com a presença eventual de clastos com dimensões entre $0,5 \mathrm{~cm}$ e $2 \mathrm{~cm}$, de basaltos, dacitose raros pelitos (Michelin, 2013). As fraturas preenchidas por sedimentos constituem-se numa feição pós magmática relativamente comum, onde os sedimentos não consolidados preenchem as fraturas existentes nas porções de topo dos derrames.

A interação entre lava e sedimentos propicia a formação de brechas (Fig. 5C). Existem inúmeras classificações para as brechas associadas a eventos vulcânicos, entre elas: Pettijohn (1975), McPhie et al. (1993), Fischer (1960), entre outros. Neste trabalho foi utilizada uma classificação de acordo com o processo de formação da brecha, sendo reconhecidos os seguintes tipos:

Brecha sedimentar: corresponde àquela formada por clastos de basaltos, andesitos e dacitos, angulosos a subarredondados, com dimensões entre 5 a 20 $\mathrm{cm}$ imersos em matriz arenosa, granulometria fina a média, quartzosa, com grãos arredondados a subarredondados de quartzo e, secundariamente, feldspato, por vezes, material argiloso associado. As brechas sedimentares são originadas por processos pós-magmáticos, localizando-se preferencialmente na porção mais superior dos derrames;

Brechas vulcânicas:com clastos angulosos, de composição muito homogênea (basaltos, andesitos ou dacitos) em uma matriz sedimentar, semelhante àquela descrita nas brechas sedimentares, porém mais argilosa. As brechas posicionam-se na base dos derrames junto ao contato com o intertrap e a partir destas ocorre a ramificação dos diques de arenito. As brechas ocorrem como camadas ou bolsões, por vezes interligados por diques clásticos irregulares, dentro da rocha vulcânica do topo dos derrames; têm matriz arenosa, os grãos apresentam contatos pontuais a flutuantes em um cimento carbonático, enquanto os clastos de rocha vulcânica vesicular (Fig. 5D) presentes são angulosos e com formas irregulares, totalmente alterados. Supõe-se que as brechas vulcânicas correspondam aos peperitos de Waichel et al. (2006). No entanto optou-se por utilizar a terminologia de brechas pois esta classificação é mais associada com reservatórios na geologia do petróleo.

Autobrechas: é uma brecha maciça caracterizada por fragmentos subangulosos a subarredondados, homogêneos de basalto ou dacito cimentados pela própia lava, carbonatos e/ou sílica. Desenvolvem-se de forma concomitante ao evento magmático e são o resultado de processos atuantes durante o movimento de derrames de lava parcialmente solidificados e, em presença de um declive na topografia.

Outro fator relevante é a tectônica, responsável por feições como falhas e fraturas que são importantes do ponto de vista do sistema permoporoso em reservatórios de rochas vulcânicas.Nas regiões analisadas (áreas de estudo 1 e 2) (Figs. 6 e 7), três direções principais são dominantes: nordeste, noroeste e leste-oeste. Essas direções são conhecidas e vem sendo registradas na Bacia do Paraná por diversos autores (Soares et al., 1982; Zalán et al., 1986; Artur \& Soares, 2002). No entanto, a despeito de ocorrerem as mesmas direções estruturais, o comportamento estrutural e morfologia das estruturas para as mesmas direções por vezes é variável entre as áreas.

Em ambas as áreas (Figs. 6 e 7) verificou-se, em lineamentos de pequeno porte, a predominância de estruturas nordeste e, secundariamente estruturas noroeste. Estas estruturas têm, em geral, o alcance de alguns quilômetros possuindo uma boa densidade nos pontos analisados, tendo porém continuidade e expressão regional restritos.

As estruturas com amplitude maior e extensões regionais são efetivamente de ocorrência mais rara, sendo geralmente descontinuas. Betiolo (2006) estudando a distribuição de lineamentos e estruturas ligadas à Formação Serra Geral, na região nordeste do Rio Grande do Sul, identificou a mesma relação entre as ocorrências, direções e quantidades de estruturas de 
pequeno e médio porte descritas no presente trabalho.

A partir da análise dos dados geomorfológicos e do modelo digital do terreno, verificou-se que na área de estudo 1 (Fig. 6) predominam duas famílias principais de direções de morfoestruturas (lineamentos), sendo também observadas outras direções que ocorrem de forma esporádica ou em lineamentos com pouca expressão espacial.

A primeira família tem direção nordeste-sudoeste com azimutes que variam em sua maior parte ao redor de $\mathrm{N} 20^{\circ} \mathrm{E}$. Esses lineamentos são os que ocorrem com maior frequência e com maior amplitude regional po- dendo ser rastreados, de forma descontínua por ordem de centenas de quilômetros na área. Em sua forma mais marcante, estes lineamentos estão associados a um sistema de extensas estruturas regionais as quais marcam formas de relevo que recortam a escarpa com vales extensos nos quais encaixam-se várias das principais drenagens da região. Estas estruturas conectam feições tectônicas menos expressivas que truncam ou são truncadas por elas. Em geral estas estruturas possuem baixo rejeito e afetam vários níveis de derrames dentro da pilha de rocha vulcânica, além de afetar por vezes a unidade sedimentar subjacente (Formação Botucatu).

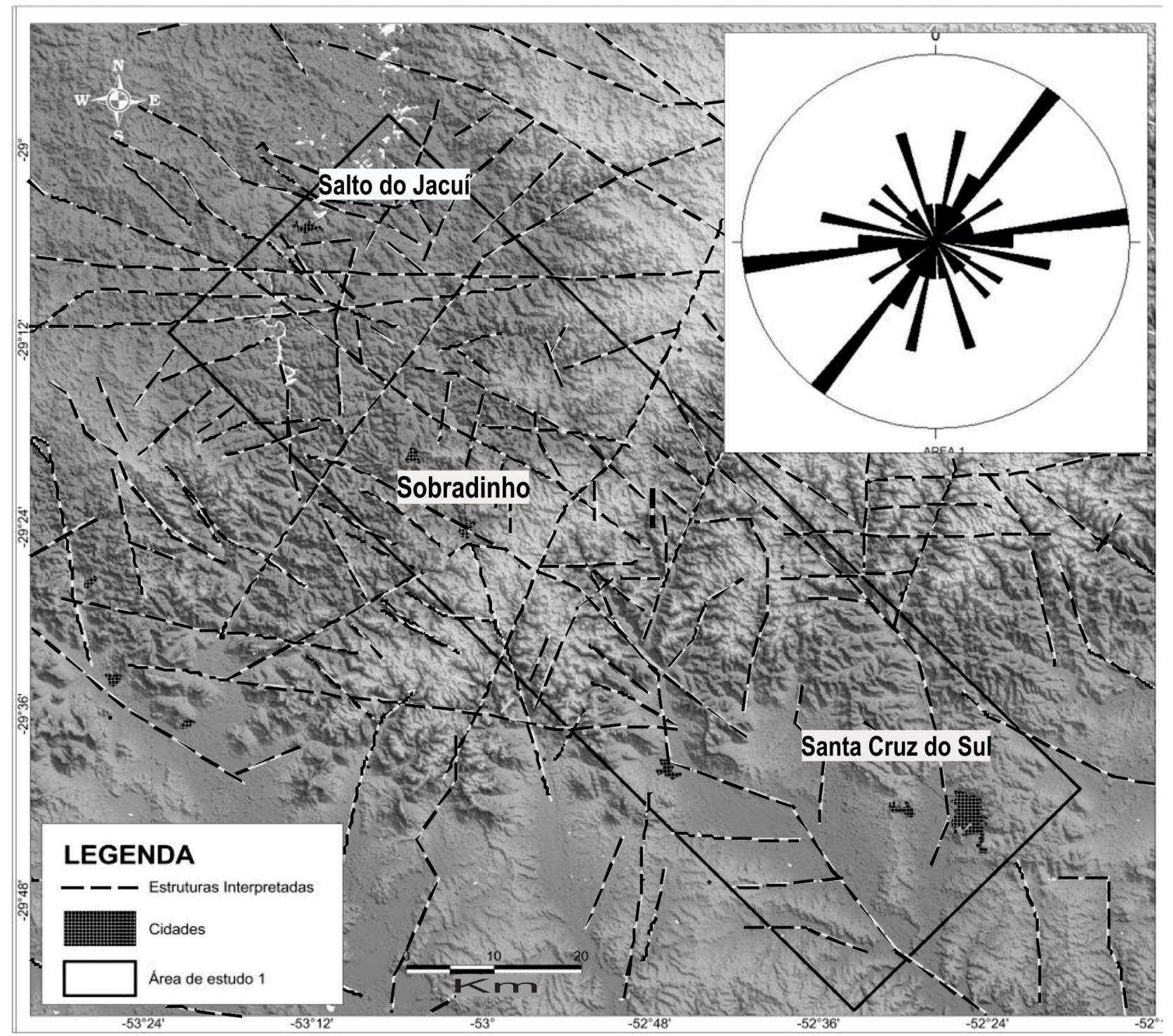

Figura 6. Mapa de modelo digital do terreno com interpretação estrutural da área de estudo 1.

Além de falhamentos, em campo, observa-se a ocorrência de fraturamentos com direção nordeste-sudoeste (direções predominantes entre $\mathrm{N} 30^{\circ} \mathrm{E}$ a $\mathrm{N} 40^{\circ} \mathrm{E}$ e $\mathrm{N} 60^{\circ} \mathrm{E}$ a $\mathrm{N}^{\circ} 0^{\circ} \mathrm{E}$ ), os quais ocorrem como amplas zonas de fraturas com largura total de metros a dezenas de metros, compostos internamente por fraturas paralelas, que cortam disjunções e outros sistemas de fraturas.

A segunda família possui direção leste-oeste, e ocorre de forma menos frequente em relação à primei- ra. Os lineamentos associados a esta direção possuem também uma amplitude regional, porém não são identificados com muita frequência.

$\mathrm{Na}$ área de estudo 2 (Fig. 7) predominam duas famílias principais de direções de lineamentos: nordeste-sudoeste e noroeste-sudeste, com ocorrência mais esporádica de lineamentos leste-oeste.Os falhamentos com direção nordeste-sudoeste ocorrem na forma de falhas simples com azimutes variáveis sendo mais 
comuns $\mathrm{N} 60^{\circ} \mathrm{E}$ e $\mathrm{N}^{\circ} 5^{\circ} \mathrm{E}$ planos com mergulhos verticalizados a subverticalizados e estrias. As estrias são indicativas da movimentação que posiciona lateralmente os diferentes derrames ou níveis dos derrames, como por exemplo zona vesicular ao lado de níveis com disjunções.
Os lineamentos leste-oeste ocorrem geralmente como morfoestruturas individuais e isoladas, com grande extensão regional, com baixa frequência, condicionando drenagens ou seccionando e direcionando as escarpas.

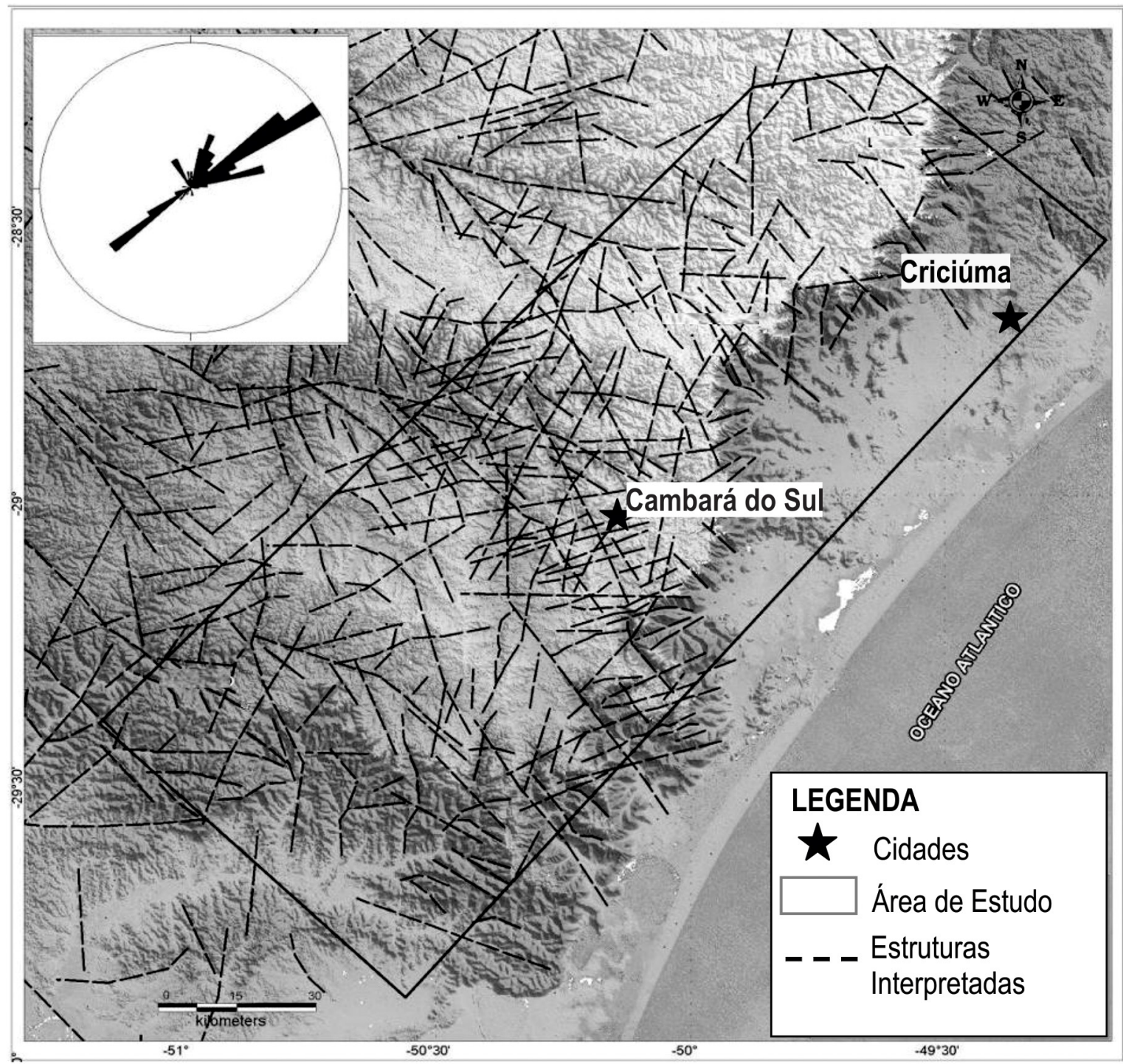

Figura 7. Mapa de modelo digital do terreno com interpretação estrutural da área de estudo 2.

\subsection{A Formação Geral como modelo de reservatório vul- cânico}

A Formação Serra Geral apresenta-se em derrames sucessivos, onde os sistemas principais de fraturamento estão relacionados a esforços tectônicos, gerando fraturas subverticais associadas as disjunções sub-horizontais (entablamentos), originadas pelos processos de resfriamento. Nos derrames e intertraps arenosos observa-se que o sistema permoporoso constitui-se da porosidade: por fraturamento, vesicular, por dissolução e microporosidade. A permeabilidade do sistema está associada com as fraturas (tectônicas e de resfriamento) e microfraturas.

As fraturas que constituem o chamado entablamento resultam do processo de resfriamento extremamente rápido da lava basáltica associado ao fluxo. São fraturas naturais e devido às suas condições de formação, não são contínuas, ou seja, são de dimensões reduzidas quando comparadas ao derrame como um todo. São geralmente horizontalizadas e descontínuas, limitando-se ao derrame onde foram formadas. Considera-se que possam ser responsáveis por porosidade nos derrames, porém esta seria muito localizada e somente efetiva quando seccionada por outras fraturas.

As fraturas tectônicas, posteriores ao evento magmático, propiciam a formação do sistema permoporoso mais importante pois, em sua maioria, interconectam-se, prolongando-se por todo o derrame e também cortam vários derrames superpostos. As estruturas tectônicas nordeste são as mais comuns nas áreas de estudo, tendo de forma geral boa distribuição espacial, com estruturas ora com expressão regional ora com pacotes com grande densidade destas. Em escala local e de 
afloramento a importância destas estruturas reside no fato de conectarem os níveis portadores de porosidade potencial dentro da sequência (zonas vesiculares, brechadas e intertraps arenosos), os diferentes derrames e os níveis porosos.

Os derrames podem ainda apresentar intenso microfraturamento associado, considerado fundamental para o desenvolvimento do sistema permoporoso, e já identificado anteriormente nas rochas igneo-básicas do Campo de Badejo (Mizusaki, 1986). As microfraturas permitem a circulação de fluidos que auxiliam na dissolução do material de preenchimento das vesículas (porosidade vesicular), o que posteriormente facilita a percolação dos fluidos (água e/ou óleo) no caso de ser um reservatório. Na realidade, a influência maior do microfraturamento parece ser no sentido de conexão de vesículas e consequente aumento de permeabilidade na zona vesicular.

A porosidade vesicular é originada pela dissolução do material de preenchimento das vesículas. Como essas feições concentram-se predominantemente no topo e na base dos derrames, a porosidade vesicular é
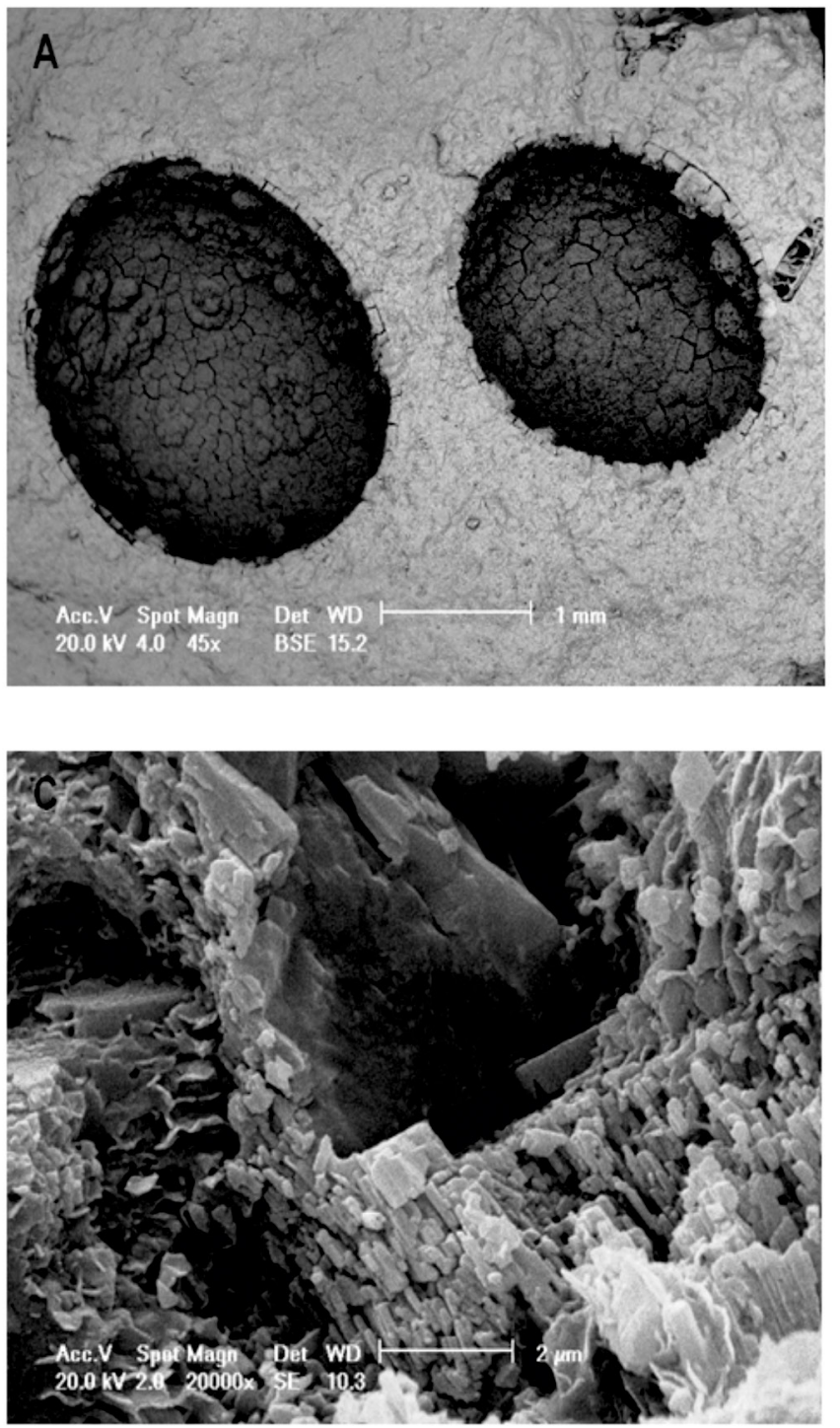

característica desses intervalos. Intervalos com porosidade vesicular apresentam a permeabilidade associada ao microfraturamento originado pelo resfriamento (Figs. 8A e 8B).

Nas amostras alteradas, com o predomínio dos argilominerais esmectita e inter-estratificado ilita-esmectita desenvolvem-se microporos. Microporos também associam-se com as alterações dos minerais primários como os feldspatos e do vidro vulcânico (Fig. 8C). Os processos intempéricos, quando atuantes, podem ocasionar não só trocas composicionais como também mudanças nas características das rochas vulcânicas aumentando os seus valores de permoporosidade, em geral, extremamente reduzidos. Verifica-se que para rochas muito alteradas há um incremento nos valores de porosidade confirmando que a microporosidade tem uma contribuição efetiva.

As zonas vesiculares da Formação Serra Geral, assim como microfraturas (Fig. 8D) e fraturas bem desenvolvidas e conectadas podem contribuir significamente para a porosidade e permeabilidade em sistemas ígneos.
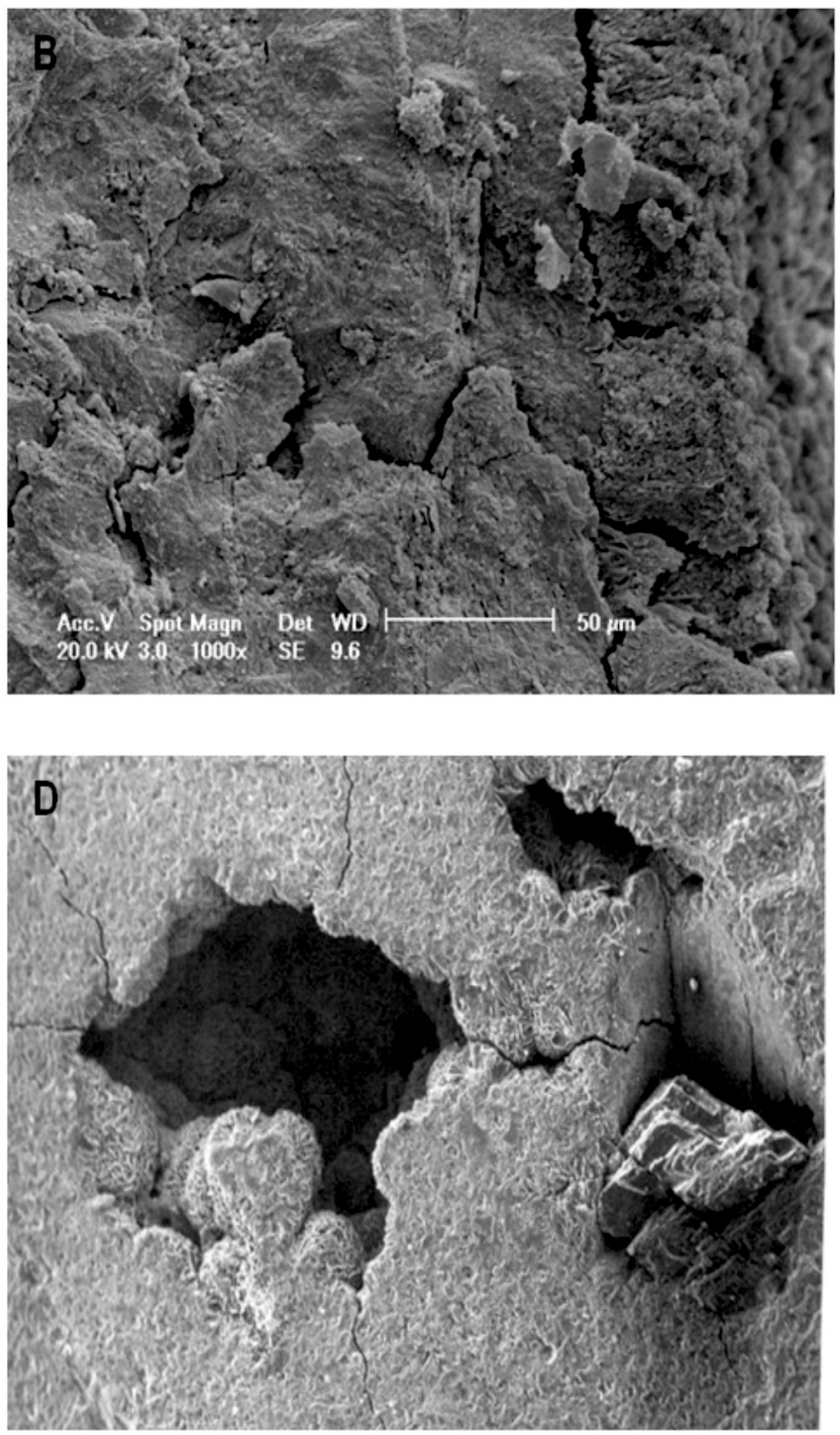

Figura 8. Detalhes do sistema permoporoso: A) porosidade vesicular em amostra da Formação Serra Geral, Bacia do Paraná (45 X, ES); B) microfraturamento (1000X, ES); C) microporos associados com processos de alteração originando microporosidade efetiva na rocha (20K, ES); D) porosidade vesicular e microfraturas em amostra da Formação Cabiúnas, Bacia de Campos (250 X, ES) 
As outras feições tais como os diques de arenito, fraturas com sedimentos, intertraps e brechas que são descritas nas áreas de estudo também foram analisadas do ponto de vista de reservatório.Os diques de arenito e as fraturas com sedimentos, em sua maioria, apresentam-se preenchidos por um arenito de granulometria fina a média com excelente porosidade (até 20\%). Na região do Salto do Jacuí eventualmente o arenito de preenchimento está cimentado por opala ou sílica microcristalina. Trata-se de uma cimentação precoce pois preserva o aspecto textural original do arenito, mostrando grãos com contatos predominantemente pontuais. Este arenito não se constitui em reservatório devido às suas dimensões restritas. Diques de arenito e fraturas preenchidas com sedimentos podem, no máximo, constituir-se em canais localizados para migração de fluidos.

Os intertraps constituem camadas de arenito com espessura de até $10 \mathrm{~m}$, com granulometria variando de fina a grossa, predominantemente quartzoso, localmente observando-se um maior teor da fração argila. Estes não se constituem em reservatórios efetivos pois são de difícil delimitação, quase sempre marcados somente pelas feições de interação entre a lava e o sedimento.

As brechas vulcânicas, sedimentares e as autobrechas ocorrem sob a forma de bolsões, na base ou no topo dos derrames. Em termos de volume, constituem uma fração muito pequena em relação aos derrames e, em relação a porosidade, sua contribuição parece ser reduzida. A porosidade associada é originada pela dissolução do cimento que origina porosidade secundária localizada. Já os sedimentos mais argilosos não apresentam porosidade primária ou secundária.

No quadro 1 pode-se verificar as diferentes feições observadas e os diferentes tipos de porosidade associados. É proposta uma qualificação e semiquantificação da porosidade verificando-se que a porosidade por fraturas é a de maior interesse.

Na figura 9, propõe-se uma seção representativa para um reservatório vulcano-sedimentar (Fig. 9A) com base nas feições observadas nas áreas selecionadas para este estudo (Fig. 9B).

Os melhores reservatórios são os derrames básicos onde domina a porosidade por faturamento (Fig. 9B, B1 e B2) e, secundariamento, a porosidade vesicular (Fig. 9B, B5) (Quadro 1). A porosidade vesicular é importante mas somente torna-se efetiva caso as vesículas sejam conectadas por microfraturas, o que origina a permeabilidade necessária ao intervalo. A microporosidade ocorre praticamente em todas as unidades mas, de uma forma geral, somente contribui para o incremento dos valores da porosidade caso haja permeabilidade associada.

Outras unidades tais como brechas e diques de arenito (Fig. 9B, B3, B4, B6) podem apresentar porosidade, mas devido às suas dimensões de pequeno porte, não formam reservatórios efetivos.

Conforme anteriormente já discutido, as fraturas tectônicas, posteriores ao evento magmático, é que propiciam a formação do sistema permoporoso mais importante pois, em sua maioria, interconectam-se, prolongam-se por todo o derrame e também cortam vários derrames superpostos.

Quadro 1. Tipos de porosidade e permeabilidade e sua ocorrência nas diferentes feições da Formação Serra Geral, Bacia de Campos - análogo como reservatório vulcânico para a Formação Cabiúnas da Bacia de Campos.

\begin{tabular}{|c|c|c|c|c|c|}
\hline Feição & Fraturas (tectônicas) & Fraturas (resfriamento) & Microfraturas & Vesiculas & Microporosidade \\
\hline Derrames básicos & $\mathbf{X X X}$ & XXX & XXX & $\mathbf{X X X}$ & XXX \\
\hline Derrames ácidos & $\mathbf{X X X}$ & $\mathbf{X}$ & $\mathbf{X}$ & $\mathbf{X}$ & $\mathbf{X X}$ \\
\hline Intertrap arenoso & $\mathbf{X}$ & - & $\mathbf{X}$ & - & $\mathbf{X X}$ \\
\hline Brechas & $\mathbf{X}$ & - & - & - & $\mathbf{X}$ \\
\hline Diques de arenito & - & - & - & - & $\mathbf{X}$ \\
\hline Fraturas com arenito & - & - & - & - & $\mathbf{X}$ \\
\hline
\end{tabular}

$\emptyset=$ porosidade $\mathrm{XXX}=$ frequente $\mathrm{XX}=$ comum $\mathrm{X}=$ raro 

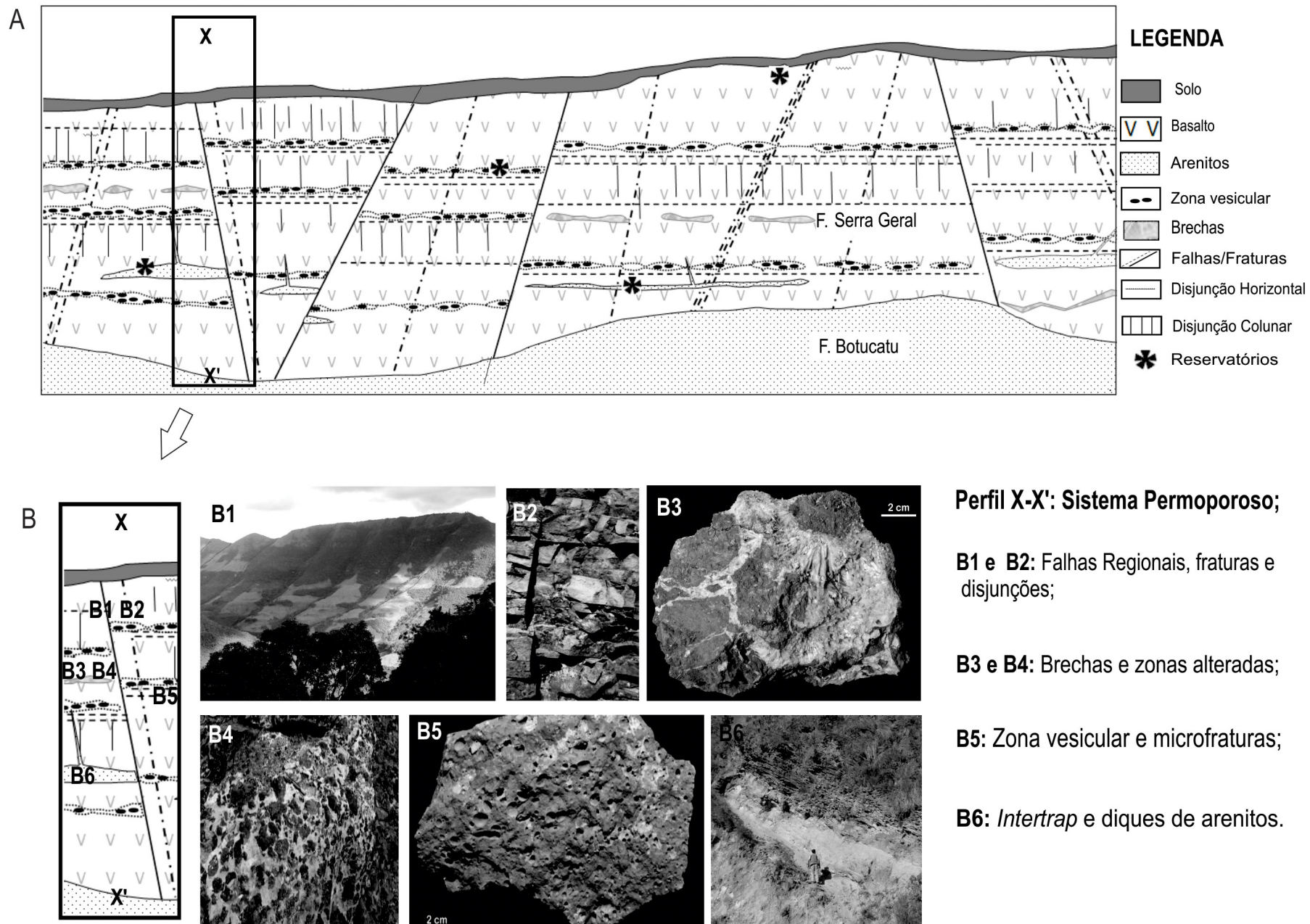

Perfil X-X': Sistema Permoporoso;
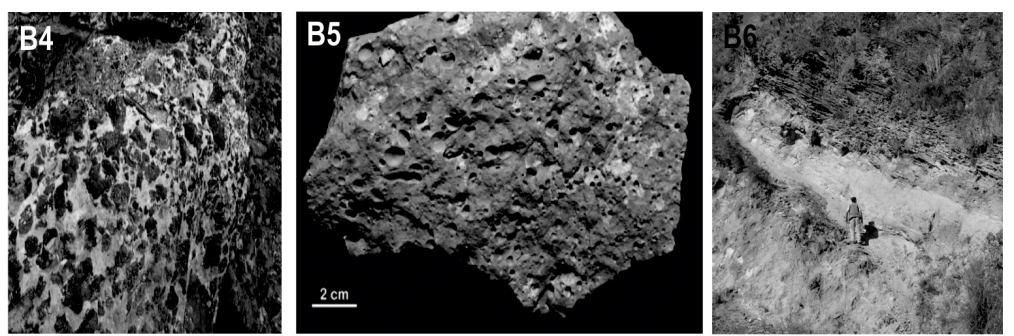

B1 e B2: Falhas Regionais, fraturas e disjunções;

B3 e B4: Brechas e zonas alteradas;

B5: Zona vesicular e microfraturas;

B6: Intertrap e diques de arenitos.

Figura 9. Modelo com base na Formação Serra Geral (Cretáceo, Bacia do Paraná) constituindo-se num análogo para os reservatórios vulcânicos da Bacia de Campos (Campos de Badejo e Linguado, Cretáceo, Formação Cabiúnas): A) Reservatório não convencional destacando os tipos de porosidade; B) Sistema permoporoso.

\section{Conclusões}

A Formação Serra Geral, observada em inúmeros e excelentes afloramentos nas regiões do Salto do Jacuí e de Torres (respectivamente porção central e sudeste do estado do Rio Grande do Sul) permitiu a proposição de um modelo de reservatório que pode indicar como seria o reservatório vulcano-sedimentar dos campos de Badejo e Linguado da Bacia de Campos.Na Formação Serra Geral, sequências de derrames basálticos intercalados com rochas vulcanoclásticas e sedimentares, onde a porosidade principal está associada ao intenso faturamento e secundariamente a vesículas e microfraturas constitui-se em modelo análogo para os reservatórios da Bacia de Campos. Este modelo confirma as proposições iniciais para o reservatório não convencional desta bacia, conforme Mizusaki (1986) permitindo concluir-se sobre a importância do estudo dos modelos análogos para o entendimento de reservatórios não convencionais em subsuperfície, especialmente os vulcano-sedimentares.

Agradecimentos- A primeira autora agradece a CAPES pela bolsa de mestrado e ao Programa de Pós Graduação em Geociências/UFRGS que permitiu a realização deste trabalho.

\section{Referências}

Artur, P.C.\& Soares, P.C. 2002. Paleoestruturas e petróleo na Bacia do Paraná, Brasil. Revista Brasileira de Geociências, 32(4):433-448.

Bellieni G., Comin-Chiaramonti, P., Marques, L.S., Melfi, A.J., Nardy, A.J.R., Papatrechas, C., Piccirillo, E.M., Roisenberg, A.\&Stolfa, D. 1986. Petrogenetic aspects of acid and basaltic lavas from the Paraná plateau (Brazil): mineralogical and petrochemical relationships. Journal of Petrology, 27:915-944.

Betiolo, L.M. 2006. Caracterização estrutural, hidrogeológica e hidroquímica dos sistemas aquiferos Guarani e Serra Geral no nordeste do Rio Grande do Sul. Porto Alegre,117p. Dissertação de Mestrado, Programa de Pós-graduação em Geociências, Instituto de Geociências, Universidade Federal do Rio Grande do Sul.

Eiras, J.F. \& Wanderley Filho, J.R. 2006. Sistemas petrolíferos igneo-sedimentares. In: CONGRESSO BRASILEIRO DE P\&D EM PETROLEO E GÁS, 2, 2006, Rio de Janeiro. Boletim de Resumos...Rio de Janeiro, SBG, v.1.

Fernandes, A.J., Maldaner, C.H., Sobrinho, J.M.A., Pressinotti, M.M.N. \& Wahnfried, I. 2010. Estratigrafia dos Derrames de Basaltos da Formação Serra Geral (Ribeirão Preto - SP) Baseada na Geologia Física, Petrografia e Geoquímica. Geologia USP, Série Científica, 10(2):73-99.

Fischer, R.V. 1960. Classification of volcanic breccias. Geologic 
Society American Bulletin, 71:973-982.

Gu, L., Zuowei, R., Wu, C., Zhao, M. \& Qiu, J. 2002. Hydrocarbon reservoirs in a trachyte porphyry intrusion in the Eastern depression of the Liaohe basin, northeast China. American Association of Petroleum Geology, 83(6):18211832.

Jinglan, L., Chengli, Z. \& Zhizhao, Q. 1999. Volcanic reservoir rocks: a case study of the Cretaceous Fenghuadian Suite, Huanghua basin, Eastern China. Journal of Petroleum Geology, 22(4):397-415.

McPhie, J., Doyle, M. \& Allen, R. 1993. Volcanic Textures. A guide to the interpretation of textures in volcanic rocks. Hobart, University of Tasmania, 198p.

Milani, E.J. 1997. Evolucão tectono-estratigráfica da Bacia do Paraná e seu relacionamento com a geodinâmica fanerozóica do Gondwana sul-oriental. Programa de Pós-graduação em Geociências, Universidade Federal do Rio Grande do Sul, Tese de Doutorado, 255p.

Mizusaki, A.M.P. 1986. Rochas ígneo-básicas do Neocomiano da Bacia de Campos - caracterização e comportamento como reservatório de hidrocarbonetos. Rio de Janeiro, 104p. Mestrado em Geociências, Programa de Pós Graduação em Geociências, Instituto de Geociências, Universidade Federal do Rio de Janeiro.

Mizusaki, A.M.P., Petrini, R., Bellieni, G., Comin-Chiaramonti, P., Dias, J., Min, A. \& Piccirillo, E.M. 1992. Basaltmagmatismalongthe passive continental marginof SE Brazil (Campos basin). Contributions to Mineralogy and Petrology, 111:143-160.

Mizusaki, A.M.P., Thomaz-Filho, A., Milani, E.J. \& Césero, P. de. 2002. Mesozoic and Cenozoic Igneous Activity andits Tectonic Control in Northeastern Brazil. Journal of South American Earth Sciences, 15:183-198.

P`An, C. H. 1983. Petroleum in basement rocks. American Association of Petroleum Geologists, Bulletin, 66(10):15971643.

Picheler, E. 1952. Diques de arenitos em Salto Grande, rio Paranapanema. Boletim da Sociedade Brasileira de Geologia, 1:15-22.

Petry, K., Jerram, D.A., Almeida, D.P.M. \& Zerfass H. 2007. Volcanic-sedimentary features in the Serra Geral Fm., Paraná Basin, southern Brazil: Examples of dynamic lava-

Manuscrito 516.

Editores: Edinei Koester \& Paulo A. Souza. sediment interactions in an arid setting. Journal of Volcanology and Geothermal Research, 159:313-325.

Pettijohn, F.J. 1975. Sedimentary rocks. New York, Harper \& Row, 628p.

Renne, P., Ernesto, M., Pacca, I.G., Coe, R.S., Glen, J.M., Prévot, M. \& Perrin, M. 1992. The age of Paraná Flood Volcanism, rifting of Gondwanaland, and the Jurassic-Cretaceous boundary. Science, 258:975-979.

Ross, J.L.S. 1985. Relevo Brasileiro: uma nova proposta de classificação. Revista do Departamento de Geografia, 4:25-39.

Ross, J.L.S. 1992 . 0 registro cartográfico e a questão da taxonomia do relevo. Revista de Geografia, 6:45-58.

Sircar, A. 2004. Hydrocarbon production from fractured basement formations. Current Science, 87(2):147-151.

Scherer, C.M.S. 1998. Análise estratigráfica e faciológica da Formação Botucatu (Cretáceo Inferior da Bacia do Paraná) no Rio Grande do Sul. Porto Alegre, 202p. Tese de Doutorado, Programa de Pós-Graduação em Geociências, Instituto de Geociências, Universidade Federal do Rio Grande do Sul.

Schiuma, M. F. 1988. Reservorios de hidrocarburos en rocas ígneas fracturadas. BIP, p. 35-45.

Soares, P.C., Barcellos, P.E. \& Csordas, S.M. 1982. Análise, interpretação e integração de lineamentos a partir de imagens (Radar-Landsat) e suas relações com a tectônica da Bacia do Paraná. São Paulo, Paulipetro, Consórcio CESP/ IPT. Relatório Interno, 382p.

Suguio, K. \& Fúlfaro, J.V. 1974. Diques clásticos e outras feições de contato entre arenitos e basaltos da Formação Serra Geral. In: CONGRESSO BRASILEIRO DE GEOLOGIA, 28, 1974, Porto Alegre. Anais... Porto Alegre, SBG, v.2, p. 107-112.

Zalán, P.V., Conceição, J.C., Wolff, S., Astolfi, M.A., Vieira, I.S., Appi, V.T., Neto, E.V.S., Cerqueira, J.R., Zanotto, O.A., Paumer, M.L. \& Marques, A. 1986. Análise da Bacia do Paraná. Relatório Interno da Petrobras. Depex/Cenpes no 10355765, Rio deJaneiro, 5 volumes.

Waichel, B.L., Lima, E.F., Lubachesky, R. \& Sommer, C.A. 2006. Pahoehoe flows from the central Paraná Continental Flood Basalts. Bulletin of Volcanology, 68(7/8):599-610. 